\title{
The Development of Repeated Severe Hypothermia in a House in a Type 2 Diabetic Patient Complicated With Klinefelter's Syndrome
}

\author{
Yoshinori Masui ${ }^{\mathrm{a}}$, Hidetaka Hamasaki ${ }^{\mathrm{a}}$, Akahito Sako, ${ }^{\mathrm{a}, \mathrm{b}}$, Sumie Moriyama ${ }^{\mathrm{a}}$, Reo Yoshikawa, \\ Hiroki Adachi ${ }^{a}$, Shuichi Mishima ${ }^{a}$, Hidekatsu Yanai ${ }^{\mathrm{a}, \mathrm{b}, \mathrm{c}}$
}

\begin{abstract}
Hypothermia is a condition in which body core temperature decreased below the temperature for normal physio-biochemical functions, which is defined as $35.0^{\circ} \mathrm{C}$. We experienced a male patient with type 2 diabetes and schizophrenia who developed severe hypothermia twice in his house, and we found that he has Klinefelter's syndrome. To our knowledge, this is the first to report the association between hypothermia and Klinefelter's syndrome. We discuss a possible association between low testosterone level and a single extra copy of the X chromosome in Klinefelter's syndrome and the development of type 2 diabetes, schizophrenia and hypothermia.
\end{abstract}

Keywords: Hypogonadism; Hypothermia; Klinefelter's syndrome; Testosterone; Type 2 diabetes

\section{Introduction}

Hypothermia is a condition in which body core temperature decreased below the temperature for normal physiological and biochemical functions, which is defined as $35.0^{\circ} \mathrm{C}$. Body temperature is usually maintained near $37.0^{\circ} \mathrm{C}$ by homeostasis or thermoregulation. We experienced a man with type 2 diabetes and schizophrenia who developed severe hypothermia twice in his house. As a result of examination of the etiology for repeated development of hypothermia, we

\footnotetext{
Manuscript accepted for publication July 20, 2012

${ }^{a}$ Department of Internal Medicine, National Center for Global Health and Medicine, Kohnodai Hospital, Chiba, Japan

${ }^{\mathrm{b}}$ Clinical Research Center, National Center for Global Health and Medicine, Kohnodai Hospital, Chiba, Japan

${ }^{\mathrm{c}}$ Corresponding author: Hidekatsu Yanai, Department of Internal Medicine, National Center for Global Health and Medicine, Kohnodai Hospital, Kohnodai 1-7-1, Ichikawa, Chiba 272-8516, Japan.

Email: dyanai@hospk.ncgm.go.jp
}

doi: http://dx.doi.org/10.4021/jem119e found that he has primary hypogonadism, Klinefelter's syndrome. To our knowledge, the association between Klinefelter's syndrome and hypothermia has not ever been discussed anywhere. Here, we will also discuss the association of Klinefelter's syndrome to the development of type 2 diabetes, schizophrenia and hypothermia.

\section{Case Report}

A 60-year-old man developed schizophrenia and type 2 diabetes in 1985 and 2004, respectively. His diabetes has been treated by dietary therapy and $\alpha$-glucosidase inhibitor, miglitol $(150 \mathrm{mg} /$ day $)$, and his recent glycemic control has been very well (HbA1c 5.7\%). In December, 2005, he slept on the floor in his house, and he developed severe hypothermia (rectal temperature, $29^{\circ} \mathrm{C}$ ) and paralytic ileus due to hypothermia. In January, 2012, he again slept on the floor in his house, and his mother noticed and warmed him by an electrical blanket to prevent hypothermia, however, he developed consciousness disturbance and admitted to our hospital. On the admission, his rectal temperature was $31.8^{\circ} \mathrm{C}$, and heart rate $(44 / \mathrm{min})$ and respiratory rare $(12 / \mathrm{min})$ were decreased. Blood gas analysis revealed hypercapnia $(\mathrm{PaCO} 2,62.0$ $\mathrm{mmHg}$ ) due to hypoventilation. Laboratory data showed elevated serum levels of aspartate aminotransferase $(214 \mathrm{U} / \mathrm{L}$; normal range, $10-40 \mathrm{U} / \mathrm{L}$ ) and alanine aminotransferase (329 U/L; normal range 5 - 40 U/L). Plasma glucose level increased to $304 \mathrm{mg} / \mathrm{dL}$, denying the existence of hypothermia due to hypoglycemia. An electrocaridogram showed Osborn waves which are observed in people suffering from hypothermia with a temperature of less than $32^{\circ} \mathrm{C}$ (Fig. 1) [1]. Active internal re-warming promptly ameliorated his consciousness, hear rate, respiration and liver function.

To reveal the etiology of his hypothermia, we performed endocrinological examinations. Diabetic retinopathy and neuropathy were not observed, and also proteinuria due to diabetic nephropathy was not detected. Serum levels of thyroid stimulating hormone, thyroid hormones and cortisol were within normal range. Blood levels of luteinizing hormone $(11.82 \mathrm{mU} / \mathrm{mL}$; normal range, $0.79-5.72 \mathrm{mU} / \mathrm{mL})$ and follicle-stimulating hormone $(19.64 \mathrm{mU} / \mathrm{mL}$; normal range, 

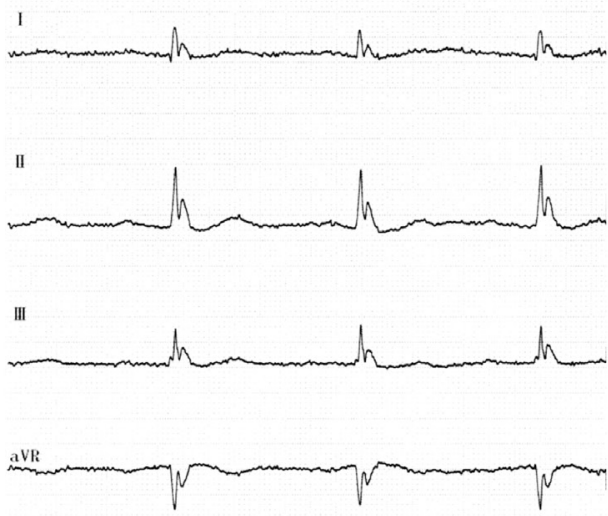

aVt.

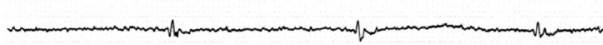

aVF

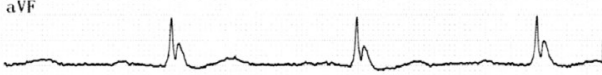

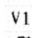

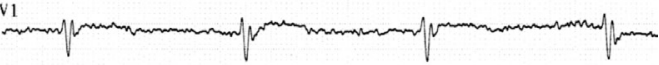

v2

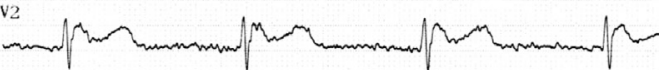
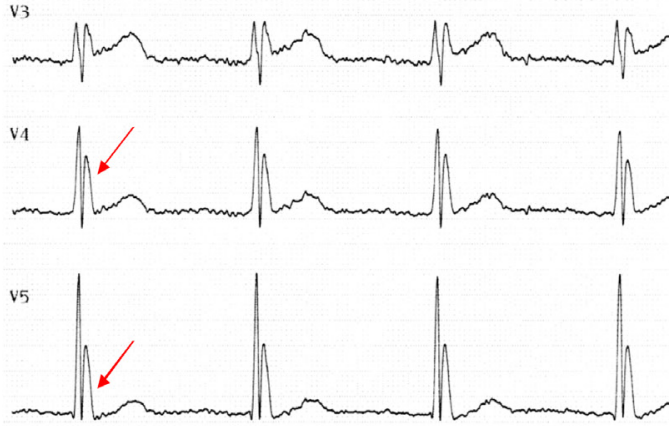

V6

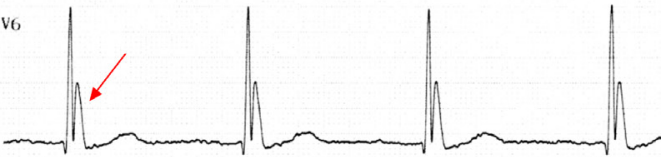

Figure 1. An electrocardiogram of the patient. Arrows indicate Osborn waves.

$2.0-8.3 \mathrm{mU} / \mathrm{mL}$ ) were significantly elevated, suggesting the existence of primary hypogonadism. Ultrasound revealed remarkable atrophy of testicles (right testicle $2.2 \mathrm{~cm}$; left testicle $1.7 \mathrm{~cm}$; normal range $4-5 \mathrm{~cm}$ ) (Fig. 2), and serum testosterone level $(0.46 \mathrm{ng} / \mathrm{mL}$; normal range, $1.31-8.7 \mathrm{ng} /$ $\mathrm{mL}$ ) was very low, confirming the diagnosis of primary hypogonadism. Chromosomal examination revealed the presence of a single extra copy of the $\mathrm{X}$ chromosome, and he has been finally diagnosed as having Klinefelter's syndrome.

\section{Discussion}

Hypothermia has been reported to be a frequent sign of severe hypoglycemia in patients with diabetes [2], however, hypoglycemia was not observed in our patient, and severe diabetic neuropathy including autonomic nervous system disturbance was not also found in our patients. Subcutaneous injection of 8-hydroxy-2-(di-n-propylamino) tetralin (8-OHDPAT), serotonin 1A receptor agonist, has been reported to cause hypothermia in mice [3]. The hypothermic effect of serotonin 1A receptor agonist was stronger in female than in male mice [3]. The hypothermic effect of serotonin 1A receptor agonist was blocked by simultaneous administration of testosterone in the ovariectomized mice, and was enhanced by castration in male mice [3]. These results suggest a significant influence of gonadal hormones on serotonin $1 \mathrm{~A}$ receptor agonist-mediated hypothermic effect. In another study, the fall in body temperature induced by rivastigmine, a pseudo-reversible carbamate inhibitor, was compared in male and female mice [4]. Testosterone decreased the temperature reduction induced by rivastigmine in gonadectomised male and female mice [4]. In also our patient, serum low level of testosterone due to Klinefelter's syndrome may

\section{R ight}

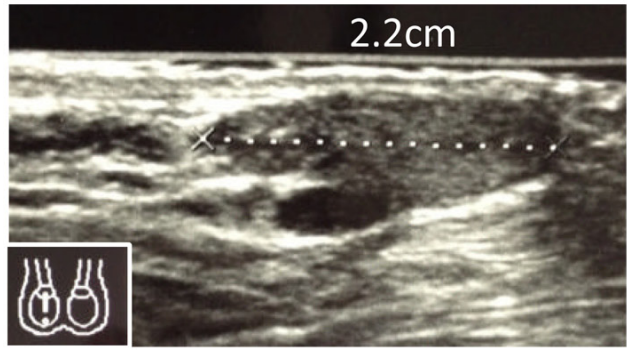

Left

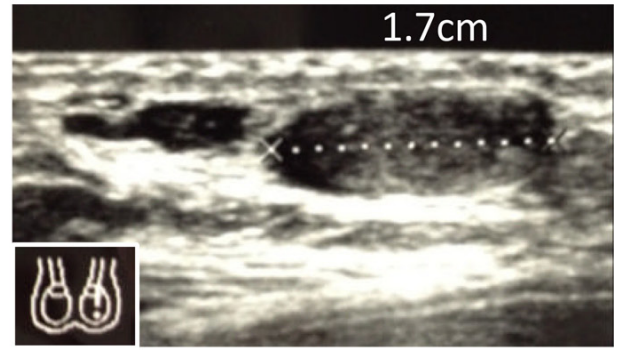

Figure 2. Ultrasound of bilateral testes. 
be associated with the development of severe hypothermia. Although further studies and accumulation of the same cases are needed, to our knowledge, this is the first to report the association between hypothermia and Klinefelter's syndrome.

Recent studies suggested an increased risk of diabetes with accumulation of body fat and decreased muscle mass and a decrease in insulin sensitivity and oxygen consumption capacity in patients with Klinefelter's syndrome [5]. Further, prospective studies in normal male populations suggest that low serum levels of testosterone can predict future development of abdominal adiposity, the metabolic syndrome and type 2 diabetes [6-9]. Low serum testosterone level due to Klinefelter's syndrome may also be associated with the development of type 2 diabetes in our patient. However, the underlying mechanism for the development of abdominal adiposity and type 2 diabetes due to low serum testosterone levels remains unknown. We speculate that testosterone-mediated thermogenesis/thermoregulation may be associated with the development of abdominal adiposity and type 2 diabetes.

High levels of schizophrenia-spectrum pathology have been observed in 32 men with Klinefelter's syndrome in comparison with 26 healthy controls, suggesting that the $\mathrm{X}$ chromosome may be involved in the development of schizophrenia [10]. X chromosome has been also reported to affect social cognitive processing and emotion regulation which are impaired in schizophrenia [11]. Klinefelter's syndrome may be associated with the development of schizophrenia in our patient.

\section{Conclusion}

To our knowledge, we report the first case with severe hypothermia possibly due to Klinefelter's syndrome. Low testosterone level and a single extra copy of the $\mathrm{X}$ chromosome may be associated with the development of type 2 diabetes, schizophrenia and hypothermia.

\section{Acknowledgement}

This work was supported by the Grant of National Center for Global Health and Medicine (22-120).

\section{Consent}

Written informed consent was obtained from a patient for publication of this case report.

\section{Authors' Contributions}

All authors were involved in study design, drafting the man- uscript and read and approved the final manuscript.

\section{Competing Interests}

The authors declare that they have no competing interests.

\section{References}

1. Marx John. Rosen's emergency medicine: concepts and clinical practice 7th edition. Philadelphia, PA: Mosby/ Elsevier. p. 1869. 2010.

2. Tran C, Gariani K, Herrmann FR, Juan L, Philippe J, Rutschmann OT, Vischer UM. Hypothermia is a frequent sign of severe hypoglycaemia in patients with diabetes. Diabetes Metab. 2012.

3. Matsuda T, Nakano Y, Kanda T, Iwata H, Baba A. Gonadal hormones affect the hypothermia induced by serotonin1A (5-HT1A) receptor activation. Life Sci. 1991;48(17):1627-1632.

4. Wang RH, Schorer-Apelbaum D, Weinstock M. Testosterone mediates sex difference in hypothermia and cholinesterase inhibition by rivastigmine. Eur J Pharmacol. 2001;433(1):73-79.

5. Bojesen A, Host C, Gravholt CH. Klinefelter's syndrome, type 2 diabetes and the metabolic syndrome: the impact of body composition. Mol Hum Reprod. 2010;16(6):396-401.

6. Tsai EC, Boyko EJ, Leonetti DL, Fujimoto WY. Low serum testosterone level as a predictor of increased visceral fat in Japanese-American men. Int J Obes Relat Metab Disord. 2000;24(4):485-491.

7. Stellato RK, Feldman HA, Hamdy O, Horton ES, McKinlay JB. Testosterone, sex hormone-binding globulin, and the development of type 2 diabetes in middleaged men: prospective results from the Massachusetts male aging study. Diabetes Care. 2000;23(4):490-494.

8. Oh JY, Barrett-Connor E, Wedick NM, Wingard DL. Endogenous sex hormones and the development of type 2 diabetes in older men and women: the Rancho Bernardo study. Diabetes Care. 2002;25(1):55-60.

9. Laaksonen DE, Niskanen L, Punnonen K, Nyyssonen K, Tuomainen TP, Valkonen VP, Salonen R, et al. Testosterone and sex hormone-binding globulin predict the metabolic syndrome and diabetes in middle-aged men. Diabetes Care. 2004;27(5):1036-1041.

10. van Rijn S, Aleman A, Swaab H, Kahn R. Klinefelter's syndrome (karyotype 47,XXY) and schizophrenia-spectrum pathology. Br J Psychiatry. 2006;189:459-460.

11. van Rijn S, Swaab H, Aleman A, Kahn RS. X Chromosomal effects on social cognitive processing and emotion regulation: A study with Klinefelter men (47,XXY). Schizophr Res. 2006;84(2-3):194-203. 